\title{
MEMPERTAHANKAN PELANGGAN DI TENGAH PERSAINGAN BANK SYARIAH DI ACEH (Studi Analisis Costumer Retention PT. LKMS MAHIRAH MUAMLAH SYARIAH Dalam Mempertahankan Loyalitas Nasabah Di Kota Banda Aceh)
}

\author{
Deni Yanuar, Munzir \\ Fakultas Ilmu Sosial dan Ilmu Politik, Universitas Syiahkuala \\ Email: deniyanuar@unsyiah.ac.id
}

\begin{abstract}
ABSTRAK
Penelitian ini bertujuan untuk mengetahui bagaimana strategi retensi pelanggan untuk mempertahankan loyalitas pelanggan di PT. LKMS Mahirah Muamalah Syariah Kota Banda Aceh. PT. LKMS Mahirah Muamalah Syariah adalah lembaga keuangan mikro di kota Banda Aceh untuk meningkatkan perekonomian, terutama di kota Banda Aceh. Teori yang digunakan dalam penelitian ini adalah Teori Kredibilitas Sumber. Fokus dari penelitian ini adalah untuk mengetahui bagaimana strategi retensi pelanggan dalam menjaga loyalitas pelanggan. Metode yang digunakan adalah analisis data dengan menggunakan pendekatan kualitatif deskriptif. Pengumpulan data dilakukan dengan menggunakan metode wawancara semi terstruktur kepada direktur PT. LKMS Mahirah Muamalah Syariah Kota Banda Aceh. Hasil penelitian ini menunjukkan bahwa peran strategi retensi pelanggan telah dilakukan oleh direktur PT. LKMS Mahirah Muamalah Syariah Kota Banda Aceh sehingga mempengaruhi loyalitas pelanggan kepada institusi.
\end{abstract}

Kata Kunci: Strategi, Retensi Pelanggan, Loyalitas, Teori Kredibilitas Sumber

\section{PENDAHULUAN}

Sejalan dengan persaingan yang semakin global banyak perusahaan sadar bahwa mereka tidak lagi dapat bersaing hanya dengan harga. Banyak perusahaan telah mengembangkan strategi jitu dalam rangka memberikan pelayanan kepada pelanggan, yaitu dengan melakukan pembedaan antara produk dan jasa mereka. Masa depan perusahaan dan persaingan antar perusahaan sangat tergantung pada kemampuan perusahaan memuaskan pelanggan.

Jika perusahaan memberikan servis yang melebihi harapan pelanggan, maka pelanggan akan puas. Pelanggan yang puas pasti akan mempunyai tingkat loyalitas yang tinggi terhadap produk perusahaan (Hermawan, 2015)

Namun dengan banyaknya persaingan perbankan yang ada di Kota Banda Aceh pada saat ini hanya fokus pada kepuasan pelanggan saja 
dirasa kurang lengkap. Banyak faktor yang menyebabkan pelanggan berpindah selain kepuasan pelanggan, antara lain banyaknya perusahaanperusahaan perbankan nasional yang sudah berdiri lama di Kota Banda Aceh.

Pada era sekarang ini banyak bank syariah yang berdiri untuk mencoba bersaing dengan bank syariah lainnya, perkembangan lembaga keuangan pada era reformasi ditandai dengan disetujuinya undang - undang No 10 Tahun 1998 yang mengatur tentang rinci landasan hukum serta jenis - jenis usaha yang dapat dioperasikan dan diimplementasikan oleh lembaga industry, perbankan syariah di Indonesia lebih banyak digerakkan oleh masyarakat (market driven). Sehingga hasilnya juga berbeda, perbankan syariah saat ini baru memiliki pangsa pasar sekitar $4,8 \%$ dari keseluruhan perbankan nasional. Perbankan syariah di Indonesia mengalami momentum percepatan pertumbuhan semenjak disahkannya UU No. 21 Tahun 2008 tentang Perbankan Syariah (Rofi'ah, 2017). Banyak cara yang dilakukan oleh pihak bank syariah dalam melakukan persaingan demi pencapaian suatu tujuan yang sekarang ini banyak berdiri bank syariah. Ketertarikan para masyarakat untuk bergabung menjadi nasabah di suatu bank syariah itu tidak terlepas dari pada pihak lembaga untuk menerapkan pelayanan yang baik dengan masyarakat ( nasabah ), di tengah - tengah ketatnya persaingan antar bank syariah di Aceh khususnya di Kota Banda Aceh.

Kesetiaan pelanggan atau loyalitas pelanggan terhadap suatu produk atau jasa, mengarahkan secara tidak langsung untuk loyal pula kepada perusahaan. Dengan adanya loyalitas pelanggan, dapat menjamin keberlangsungan hidup (kontinuitas) perusahaan dalam jangka waktu yang relatif panjang. Loyalitas akan terus berlanjut selama pelanggan merasakan dan dapat menerima nilai yang lebih baik dari perusahaan tersebut. Tidak hanya membeli dengan frekuensi tinggi tetapi juga memiliki komitmen dan sikap positif terhadap perusahaan. (Maulina, 2019)

Program customer retention merupakan suatu program untuk pelayanan pelanggan dan untuk menjaga kesetiaan pelanggan. 
Program retensi inilah benteng kekuatan yang harus di- rancang sedemikian menarik sebagai benefit yang ditawarkan dapat menyentuh pelanggan (Hardjanti \& Amalia, 2014). Costumer retention merupakan bentuk loyalitas yang berhubungan dengan perilaku yang diukur berdasarkan perilaku beli konsumen yang ditunjukkan dengan tingginya frekuensi konsumen membeli suatu produk. Sementara itu, loyalitas sendiri lebih mengacu pada sikap yang diukur berdasarkan komponen-komponen sikap, keyakinan, perasaan, dan kehendak untuk melakukan pembelian (Armawati, 2015)

\section{Costumer retention sangat} penting dilakukan oleh suatu perusahaan, dan perusahaan mulai merasa bahwa program untuk meningkatkan loyalitas pelanggan harus dan wajib dilakukan. Untuk itulah diadakan customer retention, yaitu upaya yang dilakukan oleh lembaga atau organisasi atau perusahaan agar loyalitas pelanggan meningkat, ditunjukkan melalui pelayanan yang diberikan perusahaan dimana di dalamnya terdapat program-program atau strategi yang digunakan oleh perusahaan.

Lembaga Keuangan Mikro PT. LKMS Mahirah Muamalah Syariah merupakan lembaga keuangan mikro syariah milik pemerintah Kota Banda Aceh dalam upaya untuk meningkatkan perekonomian di Kota Banda Aceh. Menjadi Badan Usaha Milik Pemerintah Kota (BUMK), Diharapkan dapat menjawab tantangan dan kebutuhan masyarakat khususnnya rakyat kecil yang membutuhkan bantuan modal mikro.

Lembaga Keuangan Mikro PT. LKMS Mahirah Muamalah Syariah juga menghadirkan berbagai produk tabungan yang mengelola keuangan masyarakat dengan prinsip - prinsip syariah. Sebagai Lembaga intermediasi yang beroperasi dengan berlandaskan pada Syariat Islam, PT. LKMS Mahirah Muamalah Syariah melakukan kegiatan penghimpunan dana berpedoman pada hukum hukum Dinul Islam, peraturan perundang - undangan dan peraturan yang dikeluarkan oleh Pemerintah maupun Otoritas Jasa Keuangan (OJK) sebagai pembina dan pengawas perbankan nasional. 
Kehadiran Bank Syariah di tengah perindustrian dan persaingan di dunia perbankan membuat dari setiap bank yang ada saling beradu untuk mencari nasabah, untuk itu diperlukan strategi costumer retention dari masingmasing bank yang ada. Costumer retention merupakan sarana yang paling ampuh untuk mempertahankan loyalitas nasabahnya.

Melalui strategi costumer retention, PT. LKMS Mahirah Muamalah Syariah dapat mempertahankan loyalitas nasabah sehingga nasabah akan tetap menggunakan jasa dari lembaga keuangan mikro PT. LKMS Mahirah Muamalah Syariah.

Hovland dalam buku Communication and Persuasion mengatakan, The Source Credibility Theory merupakan High credibility source had a substantially greater immediate effect on the audience's opinions than low credibility source. Sumber dengan kredibilitas tinggi memiliki dampak besar terhadap opini audiens daripada sumber dengan kredibilitas rendah (Hovland, 2007).

Suatu pesan persuasif akan lebih efektif apabila kita mengetahui bahwa penyampai pesan adalah orang yang ahli dibidangnya (Azwar, n.d.) Seorang komunikator dalam proses komunikasi akan sukses apabila berhasil menunjukkan souce credibility, artinya menjadi sumber kepercayaan bagi komunikan.

Teori The Source Credibility dalam menjalankan strategi Costumer Retention Lembaga Keuangan Mikro PT. LMKS Mahirah Muamalah Syariah dalam mempertahankan loyalitas nasabah di Kota Banda Aceh terbukti memiliki pengaruh yang besar. Mengingat Penggerak terdepan dari customer retention itu sendiri adalah seorang komunikator yang dituntut dapat berkomunikasi dengan baik dan efektif dengan pelanggannya. Sehingga PT. LKMS Mahirah Muamalah Syariah Kota Banda Aceh akankah mampu mempertahankan loyalitas nasabahnya untuk tetap menggunakan jasa dari PT. LKMS Mahirah Muamalah Syariah dengan jangka waktu yang panjang (kontinuitas).

Costumer retention merupakan sebuah bentuk ketertarikan batin antara pelanggan dengan produsen yang ditandai dengan pembelian yang berulang dan pada dasarnya bersifat 
jangka panjang (Kotler \& Amstrong, 2012). Tingkat perawatan yang tinggi sama dengan tingkat penyeberangan yang rendah. Secara konvensional, customer retention (perawatan pelanggan) didefinisikan sebagai jumlah pelanggan yang berbisnis dengan sebuah firma pada akhir tahun buku yang dinyatakan dengan persentase pelanggan yang merupakan pelanggan aktif pada awal tahun buku (Maklan, 2013)

\section{Costumer retention marketing}

(CRM) dipakai untuk mendukung proses I-D-I-C yaitu: Identity, Differentiate, Interact dan Custumized. Konsep I-D-I-C diperkenalkan oleh Papper dan Martha Roger dalam bukunya One to One Marketing. (Kotler, Kartajaya, \& Setiawan, 2011) (1) Identity ( identifikasi pelanggan)

Differentiate (Diferensiasi pelanggan) (3) Interact (Interaksi pelanggan) (3) Customized (Penyesuaian produk dan servis)

$$
\text { Loyalitas Pelanggan adalah }
$$

komitmen pelanggan bertahan secara mendalam untuk berlangganan kembali atau melakukan pembelian ulang produk/jasa terpilih secara konsisten dimasa akan datang, meskipun pengaruh situasi dan usahausaha pemasaran mempunyai potensi untuk menyebabkan merubah perilaku (Yuniarti \& Ariyanto, 2018)

Loyalitas merupakan asset tak ternilai bagi perusahaan, dengan tingginya loyalitas dari pelanggan, maka akan mengurangi kerawanan dari persaingan, tidak perlu adanya promosi yang berlebihan untuk menjaga pelanggan agar tidak beralih pada pesaing. Lebih lengkap menurut (Griffin, 2012) mengemukakan keuntungan-keuntungan yang akan diperoleh perusahaan apabila memiliki pelanggan yang loyal antara lain :

1. Mengurangi biaya pemasaran (karena biaya untuk menarik pelanggan baru lebih mahal).

2. Mengurangi biaya transaksi (seperti: biaya negosiasi kontrak, pemprosesan order,dll).

3. Mengurangi biaya turn over pelanggan (karena pergantian pelanggan lebih sedikit)

4. Meningkatkan penjualan silang, yang akan memperbesar pangsa pasar perusahaan 
5. Word of mouth yang lebih positif, dengan asumsi bahwa pelanggan yang loyal juga berarti mereka puas.

6. Mengurangi biaya kegagalan (seperti: biaya penggantian).

\section{METODE PENELITIAN}

Penelitian ini menggunakan pendekatan penelitian kualitatif (Moeloeng LJ, 2002). berjenis deskriptif. Teknik pengambilan data dalam penelitian ini adalah dengan menggunakan wawancara semi terstuktur, penelitian ini menggunakan lokasi di PT. LKMS MAHIRAH MUAMLAH SYARIAH di Kota Banda Aceh, data didapatkan dari hasil observasi, dokumentasi, dan wawancara, analisis yang dilakukan dengan Pengumpulan data, Reduksi data, Penyajian data, dan Penarikan Kesimpulan.

\section{HASIL DAN PEMBAHASAN}

Dalam menerapkan strategi costumer retention untuk mempertahankan loyalitas di PT. Mahirah Muamalah Syariah Kota Banda Aceh membutuhkan komunikator yang kredibel dibidangnya, program-program yang dilaksanakan bertujuan untuk mempertahankan loyalitas nasabah agar tetap menggunakan jasa PT. LKMS Mahirah Muamalah Syariah dalam jangka panjang.

Hal tersebut sangatlah sesuai dengan teori the source credibility theory dimana teori tersebut pada dasar usaha mengidentifikasi nasabahnya sesuai dengan keinginan nasabahnya sehingga mampu menciptakan strategi-strategi costumer retention dalam mempertahankan loyalitas nasabah, yaitu dengan cara melakukan pelayanan sesuai dengan keinginan nasabahnya.

The source credibility theory memiliki peran penting Teori The Source Credibility dalam menjalankan strategi Costumer Retention Lembaga Keuangan Mikro PT. LMKS Mahirah Muamalah Syariah dalam mempertahankan loyalitas nasabah di Kota Banda Aceh terbukti memiliki pengaruh yang besar. Mengingat penggerak terdepan dari customer retention itu sendiri adalah seorang komunikator yang dituntut dapat berkomunikasi dengan baik dan efektif dengan pelanggannya. 
Terciptanya hubungan dengan nasabah yang harmonis dapat memberikan dasar yang baik pula untuk memunculkan rasa ingin membeli ulang atau menggunakan jasa perusahaan tersebut secara berkelanjutan yang dalam jangka panjang akan memunculkan rasa kesetiaan. Hal ini tidak terlepas dari peran karyawan PT. LKMS Mahirah Muamalah Syariah yang mempunyai kredibilitas di bidangnya sehingga mampu menumbuhkan rasa kepercayaan nasabah kepada PT. LKMS Mahirah Muamalah.

Sumber kredibilitas yang baik sangat berpengaruh dalam menjalankan fungsi custumer retention untuk menjaga, memelihara, dan mempertahankan pelanggan yang sudah ada, dengan menjalin komunikasi yang baik dan efektif guna terjalin hubungan yang harmonis. PT. LKMS Mahirah Muamalah syariah dalam mempertahankan loyalitas nasabahnya melakukan programprogram untuk meningkatkan dan membina hubungan dengan nasabahnya melalui cara pendekatan secara langsung bersosialisasi kepada nasabah contohnya seperti sosialisasi di kantor Keucik dan Camat. Selain sosialisasi mereka juga melakukan kunjungan berkala secara rutin kepada setiap nasabah.

Setiap karyawan PT. LKMS Mahirah Muamalah Syariah dibekali dengan pelatihan-pelatihan khusus bagian marketing, pelayanan, dan karakter. Sehingga para karyawan tersebut mempunyai kredibilitas dibidangnya masing-masing agar dapat memenuhi kebutuhan dari nasabah itu sendiri.

Secara penuh dukungan kualitas personal lembaga keuangan mikro LKMS Mahirah Muamalah Syariah mampu merespon, berprilaku, sopan santun, memiliki pengetahuan dan keterampilan khusus dari seseluruh faktor-faktor proses pelayanan prima yang sekaligus mampu berkompetensi. Pelayannan yang prima merupakan salah satu cara yang di terapkan oleh direktur maupun karyawan LKMS Mahirah Mamalah Syariah Kota Banda Aceh terhadap nasabahnya yaitu dengan cara mengunjungi secara berkala terhadap nasabahnya sehingga nasabah di LKMS Mahirah Muamalah Syariah mendapat perhatian yang lebih. 
Peran direktur dan karyawan

di LKMS Mahirah Muamalah Syariah sangatlah berpengaruh besar, dalam membina hubungan dengan nasabahnya melalui program costumer retention sehingga dapat mempertahankan loyalitas nasabah agar tetap menggunakan jasa dengan jangka waktu yang lama.

Kredibilitas seorang direktur PT.LKMS Mahirah Muamalah Syariah mampu memahami permaslahan yang di hadapi oleh nasabahnya maupun mengajukan solusi disetiap nasabah yang terkendala terutama di bidang usaha mikro.

Salah satu pelayan yang diberikan oleh lembaga keuangan mikro Mahirah Muamalah Syariah Kota Banda Aceh adalah debitur pembiayaan Murabahah (jual/beli) tanpa pemotongan biaya administrasi, debitur pembiayaan murabahah yang membeli barang seharga satu juta akan dibiayai sesuai dengan dengan kebutuhan dan hasil survey di lapangan. Pola ini diterapkan untuk memberikan kemudahan layanan keuangan dan kenyamanan para debitur atau nasabah, terutama pedagang kecil menengah di Kota
Banda Aceh yang sesuai dengan Syariah.

Perkembangan PT. LKMS Mahirah Muamalah Syariah Kota Banda Aceh dari awal berdiri dari tahun 2017 hingga sekarang banyak kemajuan dan perkembangan khususnya di kalangan nasabah. Seperti yang telah diungkapkan oleh nasabah yaitu Urwatul Usqa dan M. Yanis adalah pelayanannya yang sangat baik melalui program-program yang bisa menunjang costumer retention seperti sosialisasi tentang kewirausahaan, kunjungan secara berkala dari PT. LKMS Mahirah Muamalah Kota Banda Aceh kepada nasabah setiap bulanya guna untuk mengevaluasi kendala yang dialami oleh nasabah dalam menjalankan usahanya, dan pemberian penghargaan kepada nasabah yang membayar anggsuran secara tepat waktu. Sesuai dengan pernyataan direktur PT. LKMS Mahirah Muamalah Syariah Kota Banda Aceh T. Hanansyah bahwa yang disampaikan oleh kedua nasabah bertujuan untuk mempertahankan loyalitas nasabah untuk menjadi bagian dari kemajuan dan perkembangan PT. LKMS Mahirah 
Muamalah Syariah Kota Banda Aceh. Kemudian pertumbuhan jumlah nasabah dari tahun 2017 hingga sekarang mengalami peningkatan sebanyak $12,8 \%$. Secara kemudahan bagi nasabah PT. LKMS Mahirah Muamalah Syariah Kota Banda Aceh meniadakan biaya dalam proses administrasi dibandingkan dengan lembaga keuangan yang lain.

Berdasarkan pengamatan peneliti bahwa The Source Credibility Theory secara nyata diterapkan melalui kebijakan direktur PT. LKMS Mahirah Muamalah Syariah Kota Banda Aceh yaitu bapak T. Hanansyah memberikan program seminar kewirausahaan bagi para calon nasabah, pengawasan dari tim PT. LKMS Mahirah Muamalah Syariah Kota Banda Aceh terhadap nasabah setiap bulannya kebijakan ini adalah bagian keseluruhan dari penerapan teori The Source Credibility Theory mampu mengindentifikasi kemauan nasabahnya dengan bertujuan untuk mempertahankan loyalitas nasabah di PT. LKMS Mahirah Muamalah Syariah Kota Banda Aceh melalui program costumer retention.
Dari hasil penelitian secara keseluruhan nasabah mempunyai pandangan sendiri terhadap kebijakan PT. LKMS Mahirah Muamalah Kota Banda Aceh melalui saran dan masukan agar PT. LKMS Mahirah Muamalah Syariah Kota Banda Aceh seperti tetap konsisten memberikan pelayanan terbaik seperti sekarang ini, terus juga supaya nanti semakin meningkat setiap tahunnya. Kemudian, semoga mahirah muamalah ini jadi solusi bagi seluruh masyarakat Kota Banda Aceh, khususnya yang ingin membuka usaha kecil, dan menengah di Kota Banda Aceh. 


\section{Costumer Retention PT. LKMS MAHIRAH MUAMLAH SYARIAH Dalam}

\section{Mempertahankan Loyalitas Nasabah}

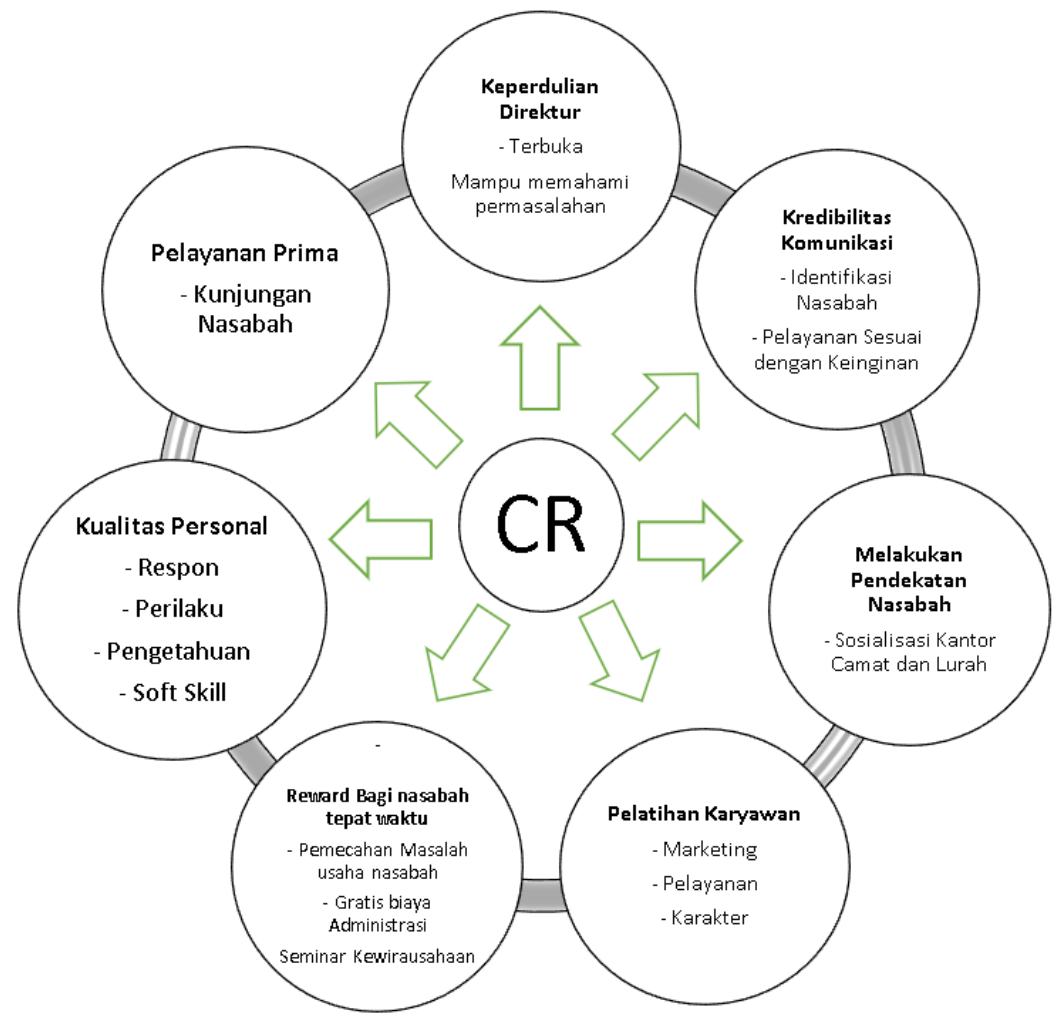

\section{KESIMPULAN}

Berdasarkan hasil penelitian dan analisis data yang dilakukan oleh peneliti, mengenai strategi costumer retention Lembaga Keuangan Mikro PT. LKMS Mahirah Muamalah Syariah dalam mempertahankan loyalitas nasabah di Kota Banda Aceh dengan The Source Credibility Theory didapatkan kesimpulan yaitu, Keuangan Mikro PT. LKMS Mahirah Muamalah Syariah dalam mempertahankan loyalitas nasabahnya menggunakan strategi costumer retention. Adapun Program-
Program yang dilakukan antara lain program-program untuk meningkatkan dan membina hubungan dengan nasabahnya melalui cara pendekatan secara langsung bersosialisasi kepada nasabah contohnya seperti sosialisasi di kantor Keucik dan Camat. Selain sosialisasi mereka juga melakukan kunjungan berkala secara rutin kepada setiap nasabah yang tepat waktu dalam membayar angsurannya. Nasabah pun merasa puas atas pelayanan yang diberikan oleh PT. 
LKMS Mahirah Muamalah Syariah Kota Banda Aceh.

\section{DAFTAR PUSTAKA}

Armawati, D. (2015). Dengan

Switching Barrier Sebagai

Pemediasi ( Studi pada

Mahasiswa Pengguna Kartu

Prabayar IM3 di Purworejo ).

Jurnal Pendidikan Surya Edukasi (JPSE), 000, 1-12.

Azwar, S. (n.d.). Sikap Manusia:

Teori dan Pengukurannya.

Yogyakarta.: Pustaka Pelajar.

Griffin, E. (2012). A First Look At Communication Theory. (S. Gouijnstook, Ed.), Wheaton College (8th ed.). McGraw-Hill. https://doi.org/10.1192/bjp.112. 483.211-a

Hardjanti, A., \& Amalia, D. (2014).

Pengaruh Customer Service Quality , Customer Perceived Value, Customer Satisfaction , Customer Trust Dan Switching Barriers Terhadap Customer Retention. Jurnal Ekonomi, $5(1), 1-12$.

Hermawan, H. (2015). Analisis

Pengaruh Bauran Pemasaran
Terhadap Keputusan, Kepuasan dan Loyalitas Konsumen Dalam Pembelian Roti Ceria di Jember. Jurnal Manajemen Dan Bisnis Indonesia, 1(2), 143-161.

Hovland, C. L. (2007). Definisi Komunikasi. Jakarta: PT. Raja Grafindo Persada.

Kotler, P., \& Amstrong, G. (2012). Marketing Management, Global Edition. Organization. https://doi.org/10.1080/0891176 0903022556

Kotler, P., Kartajaya, H., \& Setiawan, I. (2011). Marketing 3.0: From Products to Customers to the Human Spirit. Marketing 3.0: From Products to Customers to the Human Spirit. https://doi.org/10.1002/9781118 257883

Maklan, F. B. and S. (2013). Customer Relationship Management Concepts and Technologies. Journal of Chemical Information and Modeling. https://doi.org/10.1017/CBO978 1107415324.004 
Maulina, R. (2019). Meningkatkan

Loyalitas Konsumen Dalam Persaingan Bisnis.

Moeloeng LJ. (2002). Metodologi Penelitian Kualitatif. Kualitalif Sasial.

Rofi'ah, N. (2017). Analisis

Deskriptif Perkembangan
Perbankan Syariah Di Inggris (2004-2016). The Journal of Tauhidinomics, 1(2), 105-123.

Yuniarti, Y., \& Ariyanto, A. (2018). Pengaruh Serviscape Tehadap Loyalitas Pelanggan Telkomsel. Digest Marketing, 3(1), 15-22. 